\title{
Evidence that talin alternative splice variants from Ciona intestinalis have different roles in cell adhesion Richard H Singiser and Richard O McCann*
}

\author{
Address: University of Kentucky College of Medicine, Department of Molecular and Cellular Biochemistry, 741 South Limestone Street, Lexington, \\ KY 40536, USA \\ Email: Richard H Singiser - rhsing2@uky.edu; Richard O McCann* - rmcca1@uky.edu \\ * Corresponding author
}

Published: 06 December 2006

BMC Cell Biology 2006, 7:40 doi:10.1/86/|47|-2/2I-7-40

This article is available from: http://www.biomedcentral.com/I47I-2/2I/7/40

(C) 2006 Singiser and McCann; licensee BioMed Central Ltd.

This is an Open Access article distributed under the terms of the Creative Commons Attribution License (http://creativecommons.org/licenses/by/2.0), which permits unrestricted use, distribution, and reproduction in any medium, provided the original work is properly cited.

\begin{abstract}
Background: Talins are large, modular cytoskeletal proteins found in animals and amoebozoans such as Dictyostelium discoideum. Since the identification of a second talin gene in vertebrates, it has become increasingly clear that vertebrate Talin I and Talin2 have non-redundant roles as essential links between integrins and the actin cytoskeleton in distinct plasma membrane-associated adhesion complexes. The conserved C-terminal I/LWEQ module is important for talin function. This structural element mediates the interaction of talins with F-actin. The I/LWEQ module also targets mammalian Talin I to focal adhesion complexes, which are dynamic multicomponent assemblies required for cell adhesion and cell motility. Although Talin I is essential for focal adhesion function, Talin2 is not targeted to focal adhesions. The nonvertebrate chordate Ciona intestinalis has only one talin gene, but alternative splicing of the talin mRNA produces two proteins with different $C$-terminal I/LWEQ modules. Thus, $C$. intestinalis contains two talins, Talin-a and Talin-b, with potentially different activities, despite having only one talin gene.
\end{abstract}

Results: We show here that, based on their distribution in cDNA libraries, Talin-a and Talin-b are differentially expressed during $C$. intestinalis development. The I/LWEQ modules of the two proteins also have different affinities for F-actin. Consistent with the hypothesis that Talin-a and Talin-b have different roles in cell adhesion, the distinct I/LWEQ modules of Talin-a and Talin-b possess different subcellular targeting determinants. The I/LWEQ module of Talin-a is targeted to focal adhesions, where it most likely serves as the link between integrin and the actin cytoskeleton. The Talin-b I/LWEQ module is not targeted to focal adhesions, but instead preferentially labels F-actin stress fibers. These different properties of $C$. intestinalis the Talin-a and Talin-b I/LWEQ modules mimic the differences between mammalian Talin I and Talin2.

Conclusion: Vertebrates and $D$. discoideum contain two talin genes that encode proteins with different functions. The urochordate $C$. intestinalis has a single talin gene but produces two separate talins by alternative splicing that vary in a domain crucial for talin function. This suggests that multicellular organisms require multiple talins as components of adhesion complexes. In C. intestinalis, alternative splicing, rather than gene duplication followed by neo-functionalization, accounts for the presence of multiple talins with different properties. Given that $C$. intestinalis is an excellent model system for chordate biology, the study of Talin-a and Talin-b will lead to a deeper understanding of cell adhesion in the chordate lineage and how talin functions have been parceled out to multiple proteins during metazoan evolution. 


\section{Background}

The amoebozoan and animal talins (Fig. 1) are an ancient family of modular proteins that link the actin cytoskeleton to the plasma membrane in several different multicomponent adhesion complexes [1-3]. The amoebozoan cellular slime mold Dictyostelium discoideum contains two talins, each of which has a different role in the D. discoideum life cycle. TalA is required for cell motility and adhesion to the substrate in undifferentiated amoebae $[4,5]$, and TalB is required for morphogenesis during multicellular differentiation [6,7]. Vertebrates also have two talin genes, TLN1 and TLN2, which encode Talin1 and Talin2, respectively $[3,8-10]$. Talin 1 is required for cell adhesion and motility and is the primary talin component of focal adhesions $[6,7,11]$. This role for Talin 1 is analogous to that of TalA in adhesion and migration of $D$. discoideum amoebae $[4,5]$. Although Talin2 has not been completely characterized, the available evidence indicates that Talin 1 and Talin 2 have non-redundant roles in vertebrates, with Talin 2 serving as a component of stable adhesions in differentiated tissues such as striated muscle [10]. This suggests that Talin 2 may be an analog of $D$. discoideum TalB, which is required for multicellular differentiation [6,7]. Thus, at opposite ends of the large phylogenetic distance that separates amoebozoans and vertebrates within the opisthokont (i.e., animals, amoebozoans, and fungi) lineage $[3,12]$, two different talins are required for cell adhesion in distinct adhesion assemblies.

In contrast to $D$. discoideum and vertebrates, invertebrates including Drosophila melanogaster and Caenorhabditis elegans and the nonvertebrate chordate Ciona intestinalis have only one talin gene [3]. However, alternative splicing of the talin mRNA in D. melanogaster and C. intestinalis produces multiple talins that vary at their C-termini [3]. Therefore, despite having only one talin gene, multiple talin proteins can account for the biological functions of talin in these organisms.

Little is currently known about the functions of these talin splice variants. In this report we have determined that the I/LWEQ modules of the alternative splice variants of $C$. intestinalis talin have different actin-binding affinities and different subcellular targeting signals. We show that the Talin-b I/LWEQ module has a higher affinity for F-actin than the Talin-a I/LWEQ module and is also targeted to actin stress fibers in cells. In contrast, the Talin-a I/LWEQ module does not label stress fibers, but is instead targeted to focal adhesions. These differences are similar to those seen with Talin 1 and Talin 2 in vertebrates, where Talin 1 is the link between integrins and the actin cytoskeleton in focal adhesions $[11,13]$. These results suggest that alternative splicing is an effective mechanism for producing distinct talin proteins with different functions in $C$. intestinalis. The recent completion of its genome sequence has increased the utility of $C$. intestinalis as a model chordate [14-17]. Thus, further studies of Talin-a and Talin-b in C. intestinalis will be useful in identifying fundamental roles for distinct talin proteins in cell adhesion in chordates.

\section{Results \\ Identification of $\mathbf{C}$. intestinalis Talin-a and Talin-b}

During a previous analysis of the evolutionary history of amoebozoan and animal talins we determined that the $C$. intestinalis genome contains one talin gene, but that alternative splicing produces two talin proteins, based on the presence of multiple, distinct cDNA sequences in the GenBank expressed sequence tag (EST) database [3]. Like all the other talins previously identified, the full-length $C$. intestinalis talin contains an N-terminal FERM domain linked to a C-terminal I/LWEQ module by a central $\alpha$-helical rod domain [18]. In the present study we have identified multiple cDNA clones corresponding to $C$. intestinalis Talin-a and Talin-b (Table 1). These data indicate that Talin-a is perhaps more widely expressed, based on the distribution of cDNAs in the available libraries, than Talin-b. Talin-a cDNAs were found in libraries from the whole adult organism, heart, gastrula/neurula, tailbud embryo, free swimming larva, blood cells, neural complex, and testis. In addition to these C. intestinalis Talin-a cDNAs, several Talin-a ESTs were also identified from the tunicate Molgula tectiformis. Talin-b cDNAs have been identified from libraries prepared from blood cells and the adult organism. We have also identified a Talin-b EST from a cDNA library prepared from gastrula of the tunicate Ciona savignyi, so this splice variant is not restricted only to C. intestinalis (Table 1).

Comparison of the variant cDNA sequences of $C$. intestinalis with the genomic DNA sequence showed that the two cDNAs are the result of alternative splicing at the end of exon 48 of the talin transcript (Fig. 2A). The alternative final protein-coding exon 49 produces talin proteins that are $42 \%$ identical over their C-terminal 78 amino acids (Fig. 2B). This sequence divergence is greater than that between the paralogous human Talin 1 and zebrafish Talin2, which are $82 \%$ identical over the same region, and is more comparable to the divergence between human Talin 1 and Caenorhabditis elegans talin, which are 57\% identical at their C-termini. Multiple sequence alignment (Fig. 2C) of the C-termini of representative chordate talins using CLUSTAL W [19] and conversion of that alignment into an unrooted tree (Fig. 2D) using TreeView [20] illustrate the relatively high level of divergence of the C-terminus of the I/LWEQ module of $C$. intestinalis Talin-b from the other chordate talins. 
A.

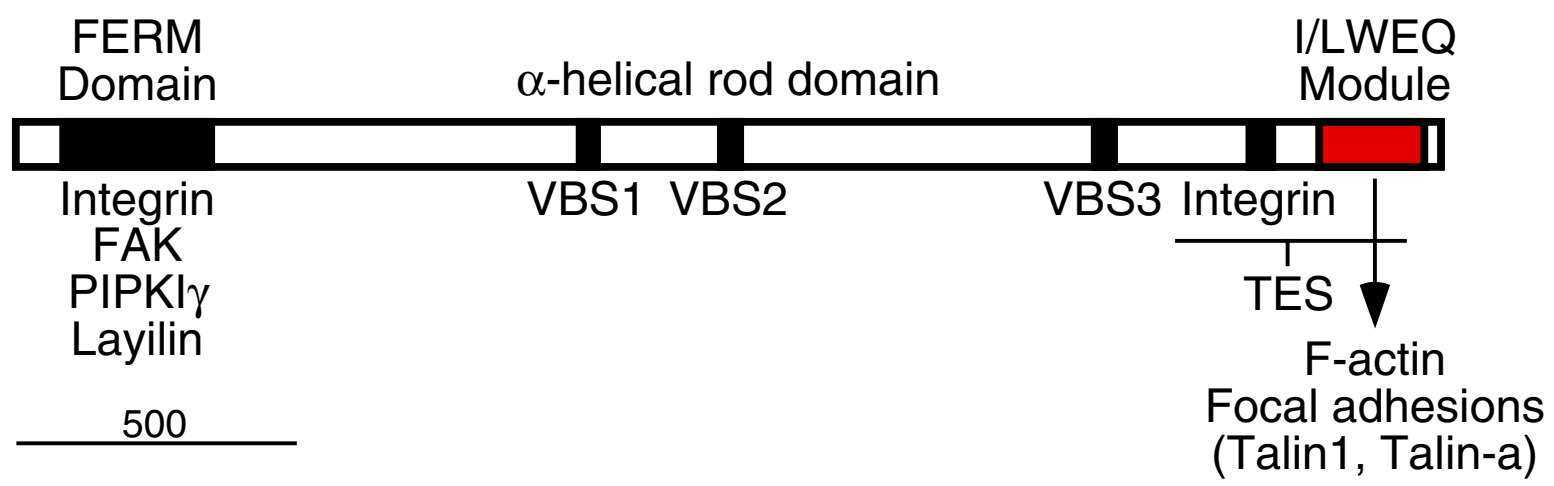

B.

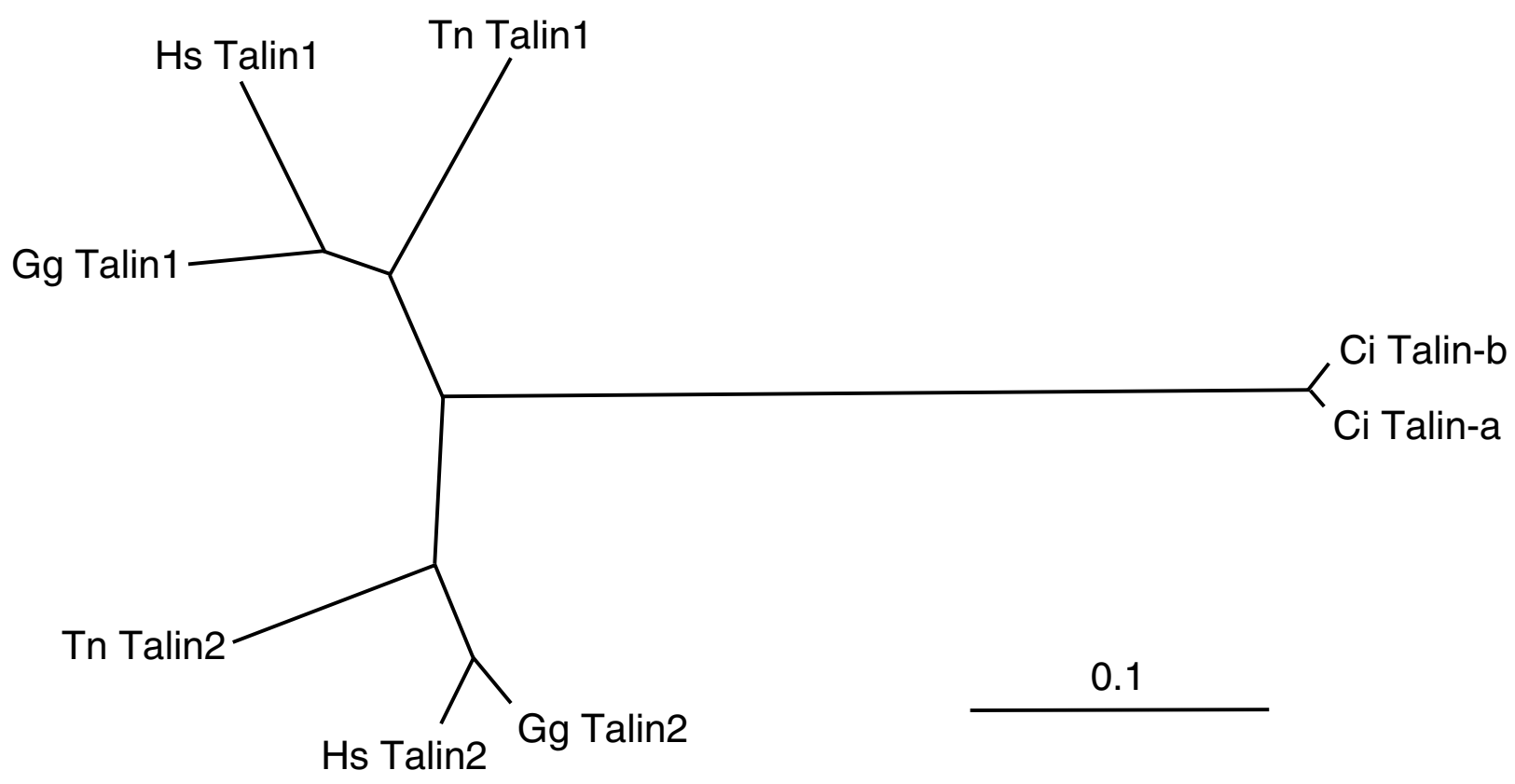

Figure I

A. Talin structure. The modular structure of talin is illustrated and representative binding sites for partners of vertebrate Talin I are indicated [I, 2, I3]. All known talins, including $C$. intestinalis talin, contain an $\mathrm{N}$-terminal FERM domain and a C-terminal I/LWEQ module [18]. The FERM domain is a conserved element that links various proteins to the plasma membrane [38]. The I/LWEQ module is a conserved F-actin-binding element that also targets Talin I to focal adhesions in mammalian cells [I3]. We show in this report that the I/LWEQ module of $C$. intestinalis Talin-a also contains a focal adhesion targeting signal. VBS: vinculin binding sites of Talin I. Scale bar: 500 amino acids. B. Unrooted tree showing the phylogenetic relationships of fulllength talins from the mammal Homo sapiens ( $\mathrm{Hs})$, the bird Gallus gallus (Gg), the pufferfish Tetraodon nigroviridis (Tn), and Ciona intestinalis $(\mathrm{Ci})$. The vertebrate Talin I and Talin2 form orthologous groups, with $C$. intestinalis Talin-a/b as the outgroup. The complete sequence alignment upon which this tree is based and an identity/similarity matrix for these talins are shown in Additional File I. Human Talin I and C. intestinalis Talin-b are $56 \%$ identical and $69.4 \%$ similar over 254 I amino acids. Scale bar: I0\% sequence divergence. 
Table I: Distribution of Talin-a and Talin-b cDNAs.

\begin{tabular}{|c|c|c|c|}
\hline Talin-a & & Talin-b & \\
\hline GenBank Accession & Source & GenBank Accession & Source \\
\hline BW500911 & adult & BW056464 & blood cells \\
\hline BW3125I5 & heart & BW050858 & blood cells \\
\hline BW261786 & gastrula/neurula & BW029542 & blood cells \\
\hline BW250883 & tailbud embryo & BW029446 & blood cells \\
\hline BW229400 & larva & BW029292 & blood cells \\
\hline BW054944 & blood cells & BW050224 & blood cells \\
\hline BW 170650 & neural complex & BW482633 & adult \\
\hline BP020498 & testis & BW5221112 & gastrula (C. savignyi) \\
\hline C) 430072 & larva (M. tectiformis) & & \\
\hline
\end{tabular}

Unambiguous Talin-a and Talin-b cDNAs were identified by comparison of the C-terminal protein sequences (Fig. 2B) with the original Talin-a and Talin-b that we have previously identified [3]. C)430072 is an EST for Talin-a from a larva cDNA library of the tunicate Molgula tectiformis; BW522112 is an EST for Talin-b from a gastrula library from Ciona savignyi. All of the other sequences are from C. intestinalis. Talin-a and Talin-b alignments of the $C$. intestinalis protein sequences derived from these ESTs are shown in Additional File 2 and Additional File 3, respectively.

\section{Actin binding activity of the Talin-a and Talin-b I/LWEQ modules}

The I/LWEQ module of talins and other members of the superfamily (e.g., fungal Sla2 and animal Hip1) specifies actin binding in these proteins $[2,9,21]$. We have recently determined that the C-terminus of the I/LWEQ module, corresponding to the splice variant sequences of $C$. intestinalis Talin-a and Talin-b, contains the minimal actinbinding site of mammalian Talin 1 [13]. This observation led us to determine whether the actin-binding affinities of the I/LWEQ modules of Talin-a and Talin-b for F-actin are different (Fig. 3). We found that the Talin-b construct binds to F-actin with an apparent $\mathrm{K}_{\mathrm{d}}$ of $0.19 \mu \mathrm{M}$, while the Talin-a I/LWEQ module bound with an apparent $\mathrm{K}_{\mathrm{d}}$ of $0.76 \mu \mathrm{M}$. These values are similar to those we previously determined for mammalian Talin 1 and Talin2, whose $K_{d}$ values were $0.31 \mu \mathrm{M}$ and $0.88 \mu \mathrm{M}$, respectively [22].

\section{Subcellular targeting of Talin-a and Talin-b}

Focal adhesions are dynamic multi-component adhesion complexes required for cell adhesion and cell motility $[23,24]$. Talin 1 is required for the assembly of focal adhesions [25], and we recently determined that the I/LWEQ module of Talin 1 is also essential for targeting this talin isoform to focal adhesions in mammalian cells [13]. Because C. intestinalis Talin-a and Talin-b vary in this subcellular targeting region of talin, we used expression of dsRed-Talin-a and dsRed-Talin-b fusion proteins to determine whether the Talin-a and Talin-b I/LWEQ modules also have different subcellular targeting determinants in mammalian cells. Interestingly, we found that the I/ LWEQ module of Talin-a strongly labels focal adhesions in HeLa cells (Fig. 4, column 1, arrowheads), where the dsRed-Talin-a fusion protein colocalized with the diag- nostic focal adhesion component vinculin (overlay). Although the Talin-a I/LWEQ module does interact with F-actin in vitro (Fig. 3), it did not preferentially label actin stress fibers in cells (Fig. 4 column 2; arrowheads identify dsRed-Talin-a in focal adhesions at the ends of stress fibers). In contrast to Talin-a, the Talin-b I/LWEQ module was not targeted to focal adhesions (Fig. 4, column 3; arrowheads identify stress fiber localization of dsRedTalin-b I/LWEQ module), but instead strongly labeled actin stress fibers in HeLa cells (Fig. 4, column 4, arrowheads), where dsRed-Talin-b I/LWEQ module colocalized with FITC-phalloidin-labeled F-actin (overlay).

\section{Discussion}

Analysis of EST data produced primarily by Nori Satoh and colleagues of Kyoto University [26] has shown that alternative splicing of talin pre-mRNA leads to the production of two proteins with different C-termini in $C$. intestinalis. The variable distributions of Talin-a and Talin$b$ in different cDNA libraries suggest that Talin-a and Talin-b are differentially expressed during $C$. intestinalis development. We have also shown that the variant I/ LWEQ modules of Talin-a and Talin-b have different biological properties: Talin-b has the higher affinity for Factin and preferentially labels actin stress fibers, while Talin-a is targeted to focal adhesions. Therefore, alternative processing is a mechanism for producing multiple talin proteins, with distinct activities associated with a critical structural element, in these nonvertebrate chordates, even though the $C$. intestinalis genome contains only one talin gene.

Alternative splicing is a widespread mechanism for expanding the proteome. In humans, $30-65 \%$ of all gene 
A.

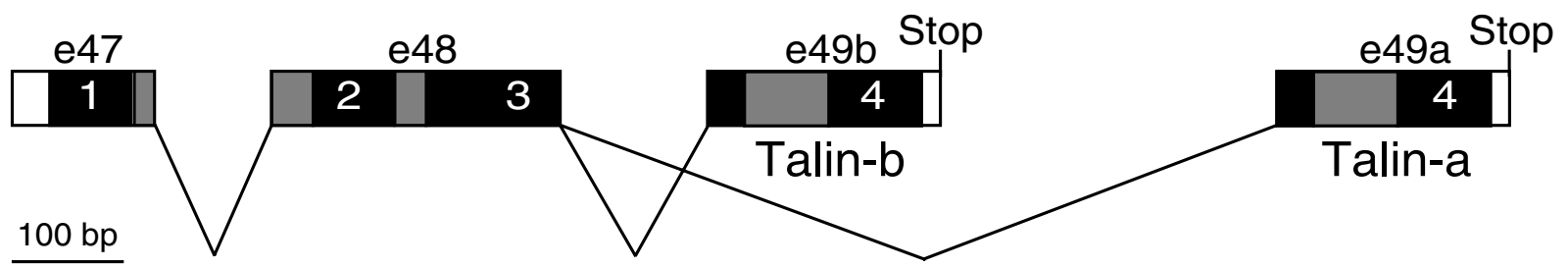

B.

$$
\text { Block } 3
$$

Block 4

Ci Talin-a IAGNAVKHASEDLVKAASESAN . SDDEVEVVINSRLVGGIAQEMMAQEEILRKERELQSARQKLAQIRRMRYKDDSESD EXon 49a Ci Talin-b TAGTAVNKATQMLVESASATFDENEEPEVELAGGLVSGIAQEMQAMEAILAKEKELKEAQVQLLKLRKKKYEQNQKK. EXON 49b

C.

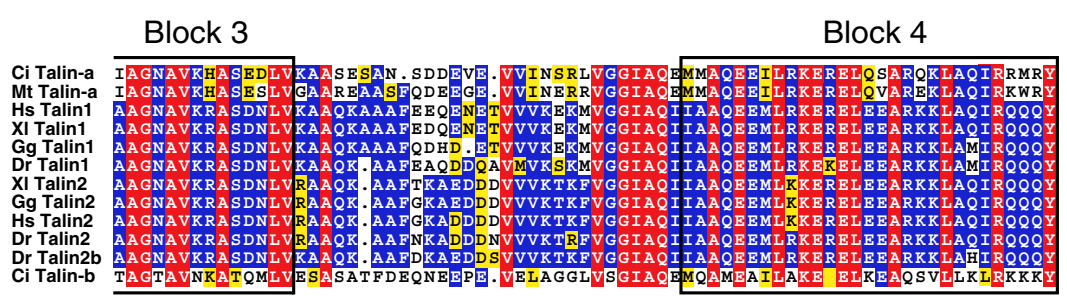

D.

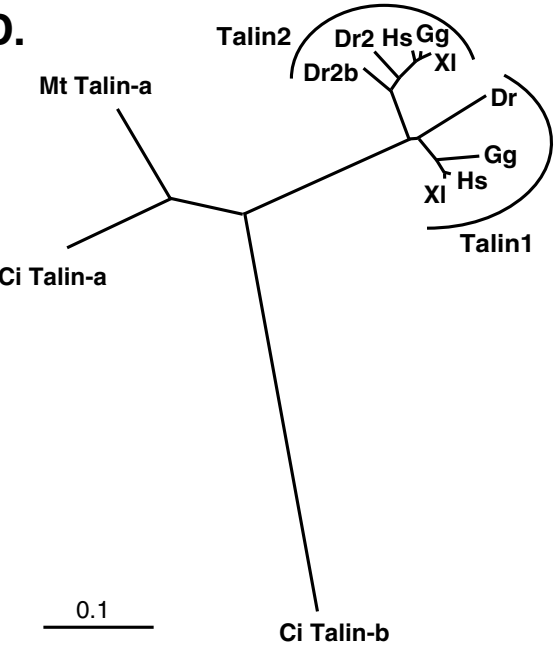

Figure 2

A. C. intestinalis alternative splice variants Talin-a and Talin-b. Exons 47, 48 and 49 encode the C-terminal I/LWEQ module of talin, which is composed of four conserved blocks (black boxes, I-4 [2]). The alternative exon 49 specifies the $78 \mathrm{C}$ terminal amino acids of either Talin-a (e49a) or Talin-b (e49b). B. Sequence comparison of Talin-a and Talin-b. The alternative splice site is near the C-terminal boundary of Block 3. The asterisks identify three sequence polymorphisms (E D, S $\mathrm{V}$, and $\mathrm{I} \mathrm{L}$ ) that were found in cDNAs isolated from two separate first-strand cDNA syntheses using total RNA from organisms from the Atlantic population of $C$. intestinalis, which is isolated from the Pacific population that was used to determine the genome sequence. Red, identical amino acids; blue, conserved changes. C. Multiple sequence alignment of representative chordate talin C-termini. The unique Talin-a and Talin-b sequences, through the final residue of Block 4 , were aligned with 10 other chordate talins using CLUSTAL W [19]. Complete description of these sequences is available in reference [3]. Red, identical amino acids; blue, conserved; yellow, similar. D. Chordate I/LWEQ module phylogenetic tree. The guide tree from the alignment of the C-termini of chordate I/LWEQ modules in (C) was used to calculate this unrooted tree [20], which shows both the conservation and divergence of the C-termini of the chordate talins. Vertebrate Talin I and Talin2 are clustered in two orthologous branches. C. intestinalis Talin-a and the Talin-a ortholog from the tunicate Molgula tectiformis also group together. The sequence divergence of $C$. intestinalis Talin-b from the other talins is illustrated by the long single branch. Species: Ci, C. intestinalis; Mt, Molgula tectiformis; Hs, Homo sapiens; XI, Xenopus laevis; Gg, Gallus gallus (chicken); Dr, Danio rerio (zebrafish). Scale bar: 10\% sequence divergence. 


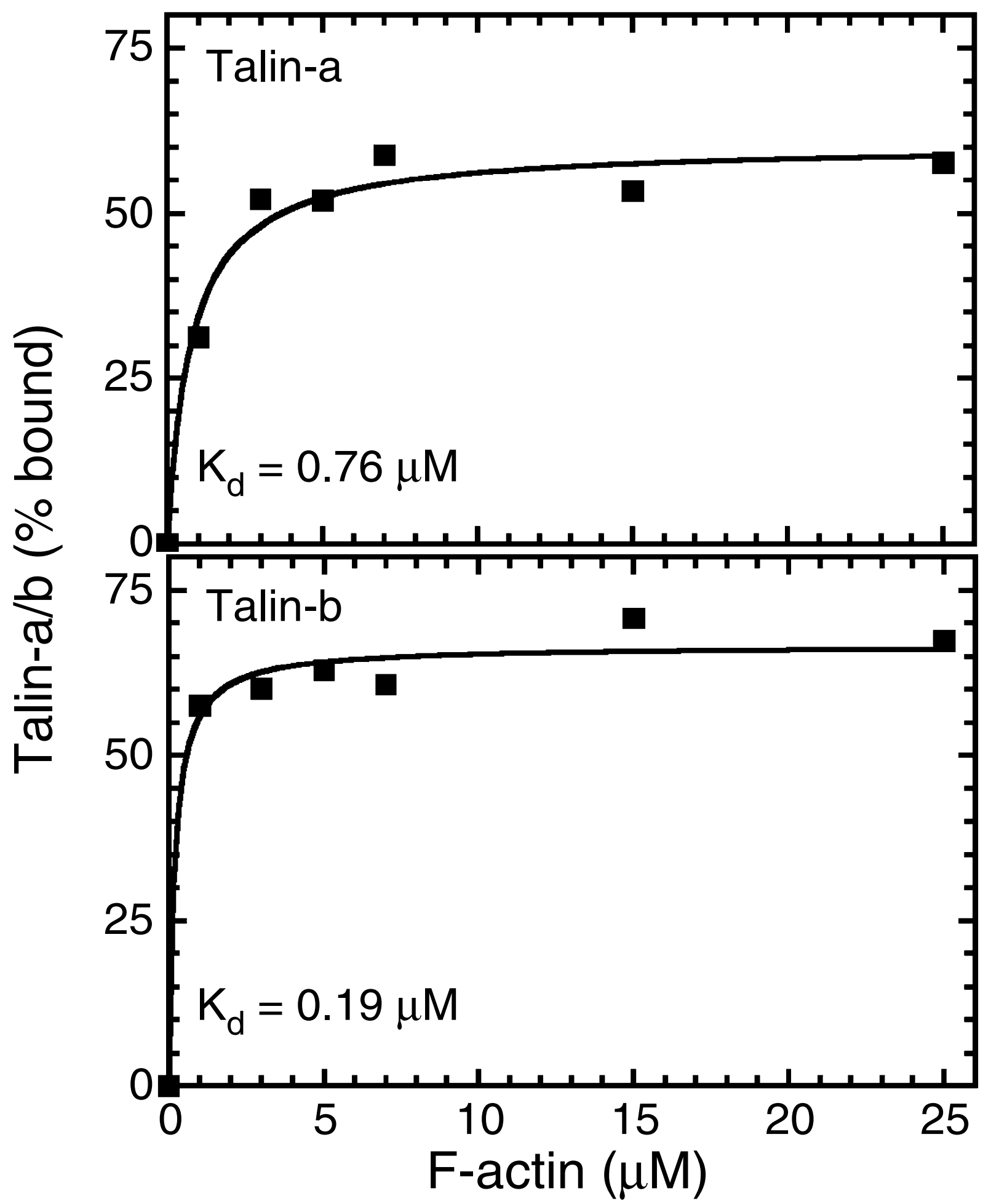

Figure 3

Actin binding of Talin-a and Talin-b I/LWEQ modules. Actin binding curves for the interaction of GST-Talin-a.234I253 I and GST-Talin-b.234I-253 I with F-actin were calculated with GraphPad Prism 4.0 as previously described [22]. The Talin-b I/LWEQ module bound to F-actin with a 4-fold higher affinity than that of Talin-a $\left(K_{d}=0.19 \mu M\right.$ vs. $\left.0.76 \mu M\right)$. Each data point is the average of three independent measurements. 
Talin-a
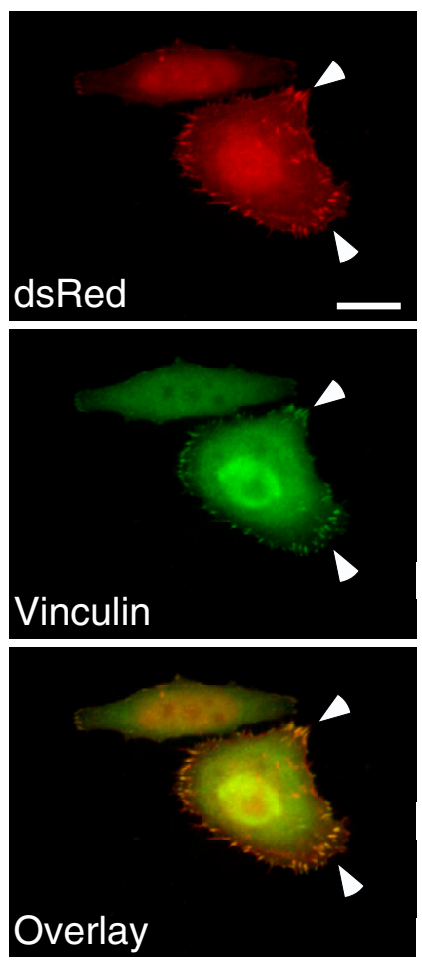
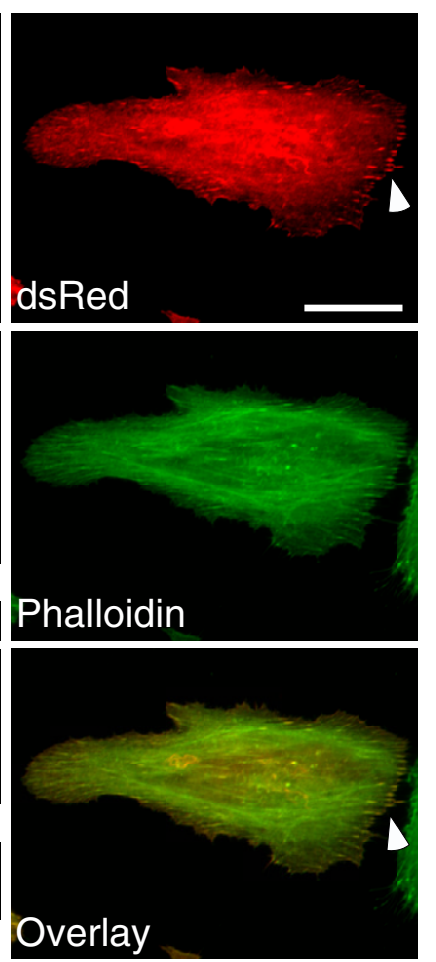

Talin-b
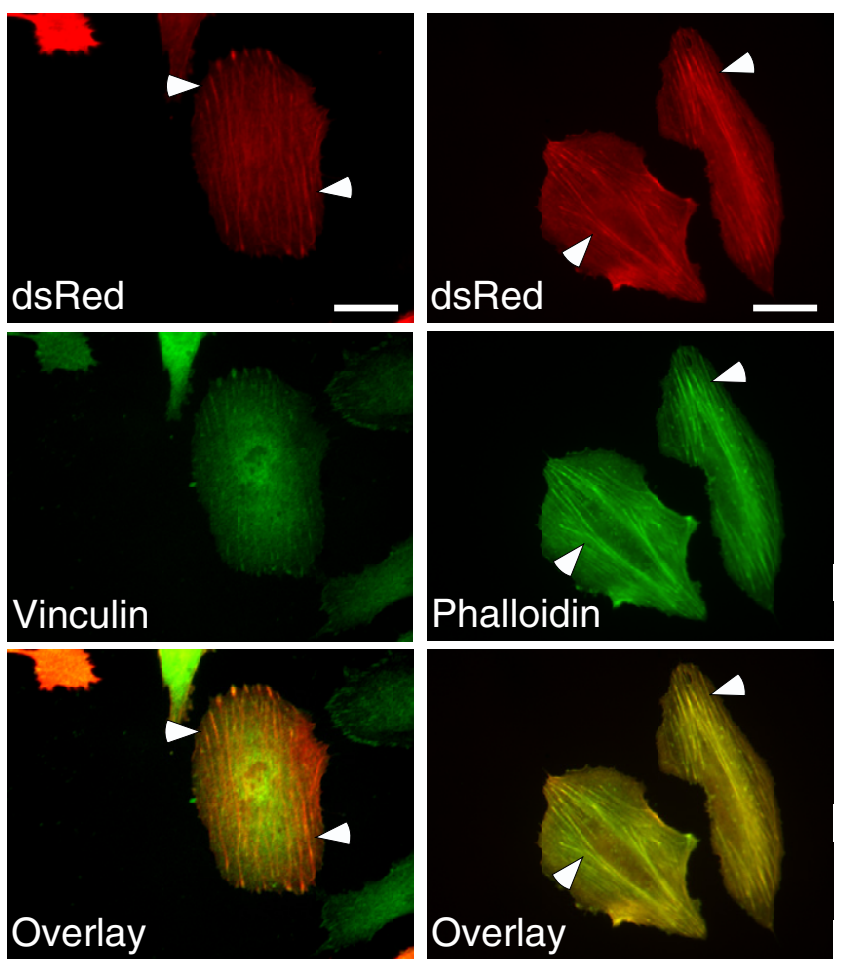

Figure 4

Subcellular targeting of the I/LWEQ modules of Talin-a and Talin-b. HeLa cells were transiently transfected with either the dsRed-Talin-a.234I-253I or the dsRed-Talin-b.234I-253I fusion construct (I/LWEQ module) and counterstained with vinculin to independently label focal adhesions or fluorescein-phalloidin to label F-actin, as previously described [I3]. The Talin-a I/LWEQ module targeted to focal adhesions, where the fluorescence signals for dsRed-Talin-a.234I-253I and the focal adhesion component vinculin overlap (Column I, overlay). The Talin-a I/LWEQ module did not preferentially localize to actin stress fibers (Column 2). In contrast to Talin-a, the Talin-b I/LWEQ module was not targeted to focal adhesions (Column 3). However, dsRed-Talin-b.234I-253I did colocalize with actin stress fibers, as shown by the colocalization of the fluorescence signals of dsRed-Talin-b.234I-253I with phalloidin-stained F-actin (Column 4, overlay).

products are subject to alternative splicing, and similar levels are also seen in other organisms, including the mouse, fruitfly, and nematode [27]. Alternative splicing frequently results in changes in protein structure that alter protein-protein interactions. For example, alternative splicing of the non-erythroid protein $4.1 \mathrm{R}$ produces variants that alter the efficiency of the interaction with the spectrin/actin complex by a factor of two [28]. This is similar to differences we have identified in the $C$. intestinalis talin alternative splice variants, where the Talin-b I/LWEQ module interacts with F-actin with a four-fold higher affinity than that of Talin-a. The higher affinity for F-actin may explain the preferential localization of the Talin-b I/ LWEQ module to actin stress fibers in cells.

Alternative splicing can also alter subcellular targeting determinants of the resultant proteins [27]. HeLa cells represent a heterologous system for the study of tunicate talins in vivo, but we have recently used them to determine that the C-terminal I/LWEQ module of Talin 1 contains a focal adhesion targeting determinant [13]. We have shown here that the Talin-a I/LWEQ module, but not that of Talin-b, is targeted to focal adhesions in HeLa cells. Although focal adhesions have not yet been directly observed in C. intestinalis cells, the C. intestinalis genome contains genes for several characteristic focal adhesion components that were previously thought to be restricted to vertebrates. These include at least $14 \alpha$-integrins, $5 \beta$ integrins, focal adhesion kinase, vinculin, and $\alpha$-actinin [15]. Vinculin and $\beta$-integrin are well-characterized Talin 1 binding partners. Given the presence of these classical focal adhesion proteins in $C$. intestinalis, our results suggest that Talin-a is likely to function similarly to mammalian Talin 1 as an adhesion complex component during $C$. intestinalis development. The lack of a focal adhesion-targeting determinant in the C-terminus of Talin-b may indi- 
cate that this protein is a component of other adhesion complexes in the organism, as we have seen with mammalian Talin2. Talin2 is not targeted to focal adhesions in undifferentiated cells but is preferentially targeted to costameres and intercalated disks, which are stable adhesions in differentiated striated muscle [10].

The presence of two related, but ancient and highly divergent talins (30\% identical) with different physiological roles in D. discoideum [4-6] supports the hypothesis that gene duplication, followed by neo-functionalization, produced multiple talins that are required for cell adhesion during cell differentiation $[3,29]$. A similar explanation may also account for the maintenance of Talin 1 and Talin2 in vertebrates since duplication of the ancestral animal talin early in the chordate lineage, more than 450 million years ago [3]. In support of this hypothesis regarding vertebrate talins, several recent studies have shown that these distinct proteins indeed have different roles. Talin 1 and Talin2 interact with different proteins $[3,30,31]$ and have different affinities for their common partner F-actin [22]. Talin1 is required for mammalian embryogenesis, probably as an essential component of adhesion complexes required for cell motility during gastrulation [32]. Talin2 is unable to complement this lethal phenotype. We have recently shown that the adult tissue distributions of mammalian Talin 1 and Talin 2 also vary, with Talin 1 being the more widely expressed isoform [10]. Talin2 is most abundant in brain and muscle. We have shown that Talin 2 is induced during muscle differentiation along with other muscle-specific proteins such as archvillin, integrin- $\beta 1_{D^{\prime}}$, and metavinculin, which is an alternative splice variant of vinculin [10]. As expected, Talin 1 is a component of focal adhesions in undifferentiated myoblasts, but Talin 2 is not found in focal adhesions of these cells or other mammalian cells. Talin2 is instead a component of stable adhesion assemblies such as costameres and intercalated disks in mature striated muscle [10]. Taken together, these studies indicate that vertebrate Talin 1 and Talin 2 are differentially expressed during cell differentiation and organismal development and that they function as non-redundant components of distinct adhesion complexes in different cells and tissues. Thus, in both $D$. discoideum and vertebrates, multiple talins are involved in talin functions.

Development in C. intestinalis is a complex, multistage process. Following fertilization and subsequent embryogenesis, a free-swimming tadpole larva containing a notochord, nervous system, and musculature settles upon a solid substrate and metamorphoses into a sessile, filterfeeding organism. The adult contains organs common to other chordates, including a digestive system, heart, and nervous system [33]. C. intestinalis has only one talin gene, but the existence of the splice variants Talin-a and Talin-b, which vary in the important C-terminal I/LWEQ module [13], further supports the emerging paradigm that talin function is due to the actions of distinct proteins, which are expressed at different times and in different places during chordate development $[3,10]$. The results presented here suggest that alternative splicing is the means by which two talins with different roles in cell adhesion, and perhaps cell differentiation, are produced from one talin gene in C. intestinalis. Thus, this mechanism may bridge the one-talin bottleneck present in invertebrates between the multicellular amoebozoan D. discoideum [34] and vertebrates [3]. Further studies at the cellular and molecular levels will identify when and where Talin-a and Talin-b are produced in C. intestinalis, and how they contribute to the assembly and function of adhesion complexes during development of this model organism.

\section{Conclusion}

Taken together with previous studies showing that talin function is due to the activities of distinct proteins, which are differentially expressed and targeted to different adhesion complexes in multicellular organisms, our results show that alternative splicing of the $C$. intestinalis talin mRNA produces two different proteins, Talin-a and Talinb. These proteins vary in the C-terminal I/LWEQ module, which is critical for talin function. Moreover, these differences lead to different activities of the alternative splice variants. Our data suggest that $C$. intestinalis Talin-a is involved in cell adhesion and motility in assemblies that are similar to focal adhesions. Identification of the structural determinants responsible for the different properties of Talin-a and Talin-b will expand our knowledge of how different talins are involved in cell adhesion in chordates. Given that $C$. intestinalis has recently re-emerged as a model for the study of chordate development [33,35], further research comparing the roles of Talin-a and Talin-b during C. intestinalis development will also increase our knowledge of how talin functions have evolved during animal evolution.

\section{Methods \\ Identification of Talin- $a$ and Talin-b}

Talin-a and Talin-b cDNAs were identified in BLAST searches [36] of the GenBank non-human, non-mouse EST database using the C-terminal 250 amino acid sequence of Ciona intestinalis talin [GenBank: AABS01000025] as the query sequence [3]. Unambiguous Talin-a and Talin-b cDNAs were identified by comparison of the C-terminal protein sequences with the original Talin-a and Talin-b that we identified previously [3]. Fulllength and partial C-terminal chordate talin sequences were aligned with CLUSTAL W [19] using the European Bioinformatics Institute server as previously described [3]. Unrooted trees were then calculated from these alignments using TreeView [20]. The sequence alignments in 
Fig. 2 were prepared for display using MacBoxShade as previously described [3].

\section{PCR amplification of Talin-alb from Ciona intestinalis and protein preparation}

Whole Ciona intestinalis adults were obtained from the Marine Biological Laboratory (Woods Hole, MA). Organisms were frozen in liquid nitrogen, pulverized, and homogenized. RNA was extracted using RNAqueous-Midi (Ambion). First strand cDNA was synthesized using Superscript II reverse transcriptase (Invitrogen) with $1 \mu \mathrm{g}$ total RNA and the oligo dT primer (5'-GACTCGAGTCGACATCGATTTTTTTTTTTTTTTTT- 3 '). Talin-a/b regions were then amplified by PCR using gene specific primers with the first-strand cDNA as a template: Talin-a/b sense, $5^{\prime}$ CCGGAATTCATTTTGGAAGCCGCAAAATCAATCGC-3' Talin-a antisense, 5'-CCTGGCGCGCCTTAATCGGATTCAGAATCATCCTTGT-3' Talin-b antisense, 5'CCTGGCGCGCCCTATTTCTTTTGGTTTTGCTCGTATTTC3' PCR amplicons were recovered using pCR2.1-TOPO (Invitrogen) and then subcloned into pET-41 (Novagen) for production of GST-fusion proteins. The proteins produced correspond to amino acids 2341-2531 for both Talin-a and Talin-b. All constructs were verified by DNA sequencing. Recombinant GST fusion proteins were prepared as previously described $[2,22]$.

\section{F-Actin Binding}

Actin was obtained from Cytoskeleton, Inc (Denver, CO). The binding of the I/LWEQ modules of Talin-a and Talin$\mathrm{b}$ to F-actin was determined as previously described $[2,22]$. Briefly, F-actin co-sedimentation assays were per-

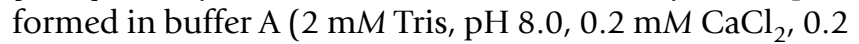
$\mathrm{mM}$ ATP, and $0.5 \mathrm{mM}$ dithiothreitol), keeping the concentration of GST-Talin-a/b.2341-2531 constant at 4.0 $\mu M$ while increasing the actin concentration from 0 to 25 $\mu \mathrm{M}$ in a total volume of $50 \mu \mathrm{l}$. Actin polymerization was induced by addition of $2 \mathrm{mM} \mathrm{MgCl}{ }_{2}$ and $50 \mathrm{mM} \mathrm{KCl}$ and allowed to proceed for 60 minutes at $22^{\circ} \mathrm{C}$. The critical concentration for actin polymerization is $0.71 \mu \mathrm{M}$ under these conditions. Following centrifugation at $160000 \mathrm{~g}$ for 20 minutes at $22^{\circ} \mathrm{C}$, the supernatant and pellet fractions were separated for subsequent analysis with SDS-PAGE using $12 \%$ gels. Proteins were stained with Coomassie Blue G250. Digital quantification of the cosedimentation data was performed using NIH Image v1.62 and binding curves were calculated using GraphPad Prism 4.0 as previously described $[2,22]$. The $\mathrm{R}^{2}$ values for the binding curves were 0.95 for Talin-a and 0.99 for Talin-b. Neither GST-Talin-a.2341-2531 nor GST-Talin-b.2341-2531 sedimented at $160,000 \mathrm{~g}$ in the absence of F-actin. We have determined previously that the presence of the GST purification tag has no effect on actin binding of I/LWEQ module proteins $[2,22]$. The concentration of actin was determined using its molar extinction coefficient at 290 $\mathrm{nm}$. The concentrations of GST-Talin-a and GST-Talin-b were determined using the BCA protein assay (Pierce) and by calculating the extinction coefficient of each protein [37].

\section{Immunofluorescence}

C. intestinalis Talin-a/b I/LWEQ module constructs were subcloned from pET-41 to pDsRedC2-monomer (BD Biosciences) and verified by DNA sequencing. HeLa cells (American Type Culture Collection CCL-2) were maintained in Dulbecco's modified Eagle's medium (DMEM) supplemented with $10 \% \mathrm{FBS}, 100 \mu \mathrm{g} / \mathrm{ml}$ penicillin, 100 $\mu \mathrm{g} / \mathrm{ml}$ streptomycin and $10 \mu \mathrm{g} / \mathrm{ml}$ gentamicin. Glass coverslips were ethanol-washed and coated with $10 \mu \mathrm{g} / \mathrm{ml}$ fibronectin. HeLa cells were plated on the coverslips in complete growth medium and allowed to adhere for 12 hours. Transfection of HeLa cells was performed with Lipofectamine 2000 (Invitrogen, Carlsbad, CA). Cells were transfected with $0.8 \mu \mathrm{g}$ of DNA and $2 \mu \mathrm{l}$ Lipofectamine 2000 in normal growth medium for 24 hours. Cells were then fixed with $4 \%$ paraformadehyde, permeabilized briefly on ice with $1 \%$ Triton X-100, and labeled with either anti-vinculin antibody at a dilution of 1:300 (V9131, Sigma) or FITC-phalloidin at 1:400 dilution as previously described in our analysis of the subcellular targeting of mammalian Talin1 [13]. Fluorescence images were obtained with a Zeiss Axiovert 200 microscope and processed using OpenLab (Improvision). Expression of intact dsRed-Talin-a/b constructs in transfected cells was confirmed in immunoblots using an anti-dsRed polyclonal antibody. We have shown previously that the addition of a fluorescence tag to the N-terminus of both full-length talin and talin I/LWEQ module constructs has no effect on the talin subcellular targeting $[10,13]$. Transfection of HeLa cells with the dsRed vector alone did not affect the morphology of HeLa cells and dsRed protein was diffusely distributed throughout the cytoplasm.

\section{Authors' contributions}

RM conceived of this work, provided advice on the design of the experiments, and provided funding. RS executed the experiments in this study. The manuscript was written by both authors. 


\section{Additional material}

\section{Additional File 1}

Alignment of full-length chordate talin protein sequences. A. Chordate talin sequence alignment. Talin1 and Talin2 from human (Hs, Homo sapiens), chicken ( $\mathrm{Gg}$, Gallus gallus), pufferfish (Tn, Tetraodon nigroviridis), and Ciona intestinalis ( $\mathrm{C} i \mathrm{Tn}-\mathrm{a} / \mathrm{b})$ were aligned using CLUSTAL W. The T. nigroviridis sequences are from the Genoscope database [39] and have been annotated manually. The G. gallus Talin2 sequence was compiled manually from the current version of the chicken genome (GenBank). The gap at position 1789-1830 corresponds to exon 40 of the human Talin $1 / 2$ sequences and may represent an unsequenced region of the chicken genome, or chicken Talin 2 may lack this exon altogether. The insertion at position 12-13 shows that $\mathrm{C}$. intestinalis talin is orthologous to vertebrate Talin2. The I/LWEQ module begins at position 2345 of human Talin1 (ILEAAK). The alternative splice variants of $\mathrm{C}$. intestinalis Talin-a and Talin-b are shown in red. Sequence identity $\left({ }^{*}\right)$; sequence similarity (:). An unrooted tree based on this alignment is shown in Fig. 1. B. Identity/similarity matrix of chordate talins. Percent sequence identity is shown below the diagonal; percent sequence similarity is shown above the diagonal. Matrix values were calculated using MacBoxShade

Click here for file

[http://www.biomedcentral.com/content/supplementary/14712121-7-40-S1.doc]

\section{Additional File 2}

Alignment of $\mathrm{C}$. intestinalis Talin-a protein sequences. Protein sequences are from the EST sequences listed in Table 1. The alternatively spliced exon sequence is in red.

Click here for file

[http://www.biomedcentral.com/content/supplementary/1471-

2121-7-40-S2.doc]

\section{Additional File 3}

Alignment of C. intestinalis Talin-b protein sequences. Protein sequences are from the EST sequences listed in Table 1. The alternatively spliced exon sequence is in red.

Click here for file

[http://www.biomedcentral.com/content/supplementary/14712121-7-40-S3.doc]

\section{Acknowledgements}

The work was supported by research grants from the National Institutes of Health (P2ORR2017I) and the Ohio Valley Affiliate of the American Heart Association (03652 I8B) to R.O. McCann. R.H. Singiser is supported by a predoctoral fellowship from the Ohio Valley Affiliate of the American Heart Association (06/526IB).

\section{References}

I. Critchley DR: Talin. In Guidebook to the Extracellular Matrix, Anchor and Adhesion Proteins Edited by: Kreis T, Vale R. Oxford, Oxford University Press; 1999:82-85.

2. McCann RO, Craig SW: The I/LWEQ module: a conserved sequence that signifies $F$-actin binding in functionally diverse proteins from yeast to mammals. Proc Natl Acad Sci U S A 1997, 94(I I):5679-5684.

3. Senetar MA, McCann RO: Gene duplication and functional divergence during evolution of the cytoskeletal linker protein talin. Gene 2005, 362:14I-152.

4. Kreitmeier M, Gerisch G, Heizer C, Muller-Taubenberger A: A talin homologue of Dictyostelium rapidly assembles at the lead- ing edge of cells in response to chemoattractant. J Cell Biol 1995, I29(I): 179-188.

5. Niewohner J, Weber I, Maniak M, Muller-Taubenberger A, Gerisch G: Talin-null cells of Dictyostelium are strongly defective in adhesion to particle and substrate surfaces and slightly impaired in cytokinesis. J Cell Biol I997, I38(2):349-36I.

6. Tsujioka M, Machesky LM, Cole SL, Yahata K, Inouye K: A unique talin homologue with a villin headpiece-like domain is required for multicellular morphogenesis in Dictyostelium. Curr Biol 1999, 9(7):389-392.

7. Tsujioka M, Yoshida K, Inouye $K$ : Talin B is required for force transmission in morphogenesis of Dictyostelium. Embo J 2004, 23( I I):2216-2225

8. McCann RO, Craig SW: Identification of a novel isoform of the focal adhesion protein talin. Mol Biol Cell 1998, 9 (Suppl S Nov 1998):798.

9. McCann RO, Craig SW: Functional genomic analysis reveals the utility of the I/LWEQ module as a predictor of protein:actin interaction. Biochem Biophys Res Commun 1999, 266(I): I35-I 40.

10. Senetar MA, Moncman CL, McCann RO: Talin2 is Induced During Striated Muscle Differentiation and is Targeted to Stable Adhesion Complexes in Mature Muscle. Cell Motil Cytoskel 2006, In press:.

II. Franco SJ, Rodgers MA, Perrin BJ, Han J, Bennin DA, Critchley DR, Huttenlocher A: Calpain-mediated proteolysis of talin regulates adhesion dynamics. Nat Cell Biol 2004, 6:977-983.

12. Baldauf SL: The deep roots of eukaryotes. Science 2003, 300: 1703-1706.

13. Franco SJ, Senetar MA, Simonson W, Huttenlocher A, McCann RO: The conserved C-terminal I/LWEQ module targets Talin I to focal adhesions. Cell Motility and the Cytoskeleton 2006, 63:563-58I.

14. Dehal P, Satou Y, Campbell RK, Chapman J, Degnan B, De Tomaso A, Davidson B, Di Gregorio A, Gelpke M, Goodstein DM, Harafuji N, Hastings KE, Ho I, Hotta K, Huang W, Kawashima T, Lemaire P, Martinez D, Meinertzhagen IA, Necula S, Nonaka M, Putnam N, Rash S, Saiga H, Satake M, Terry A, Yamada L, Wang HG, Awazu S, Azumi K, Boore J, Branno M, Chin-Bow S, DeSantis R, Doyle S, Francino P, Keys DN, Haga S, Hayashi H, Hino K, Imai KS, Inaba K, Kano S, Kobayashi K, Kobayashi M, Lee BI, Makabe KW, Manohar C, Matassi G, Medina M, Mochizuki Y, Mount S, Morishita T, Miura S, Nakayama A, Nishizaka S, Nomoto H, Ohta F, Oishi K, Rigoutsos I, Sano M, Sasaki A, Sasakura Y, Shoguchi E, Shin-i T, Spagnuolo A, Stainier D, Suzuki MM, Tassy O, Takatori N, Tokuoka M, Yagi K, Yoshizaki F, Wada S, Zhang C, Hyatt PD, Larimer F, Detter C, Doggett N, Glavina T, Hawkins T, Richardson P, Lucas S, Kohara $Y$, Levine M, Satoh N, Rokhsar DS: The draft genome of Ciona intestinalis: insights into chordate and vertebrate origins. Science 2002, 298(560I):2157-2167.

15. Sasakura Y, E. S, Takatori N, Wada S, Meinertzhagen IA, Satou Y, Satoh N: A genomewide survey of developmentally relevant genes in Ciona intestinalis $\mathbf{X}$. Genes for cell junctions and extracellular matrix. Dev Genes and Evolution 2003, 213:303-313.

16. Holland LZ, Gibson-Brown J]: The Ciona intestinalis genome: when the constraints are off. Bioessays 2003, 25(6):529-532.

17. Canestro C, Bassham S, Postlethwait JH: Seeing chordate evolution through the Ciona genome sequence. Genome Biol 2003 , 4(3):208

18. Bateman A, Coin L, Durbin R, Finn RD, Hollich V, Griffiths-Jones S, Khanna A, Marshall MS, Moxon S, Sonnhammer EL, Studholme DJ, Yeats C, Eddy SR: The Pfam protein families database. Nucleic Acids Res 2004, 32:DI38-D I4I.

19. Thompson JD, Higgins DG, Gibson TJ: CLUSTAL W: improving the sensitivity of progressive multiple sequence alignment through sequence weighting, position-specific gap penalties and weight matrix choice. Nucleic Acids Res 1994, 22(22):4673-4680.

20. Page RD: TreeView: an application to display phylogenetic trees on personal computers. Comput Appl Biosci 1996, I 2(4):357-358.

21. Engqvist-Goldstein AE, Kessels MM, Chopra VS, Hayden MR, Drubin $D G$ : An actin-binding protein of the Sla2/Huntingtin interacting protein-I family is a novel component of clathrin-coated pits and vesicles. / Cell Biol 1999, I47(7):1503-1518.

22. Senetar MA, Foster SJ, McCann RO: Intrasteric Inhibition Mediates the Interaction of the I/LWEQ module proteins Talin I, 
Talin2, Hip I, and Hip 2 with Actin. Biochemistry 2004, 43:154|8-15428.

23. Critchley DR: Focal adhesions - the cytoskeletal connection. Curr Opin Cell Biol 2000, I 2(I): 133-139.

24. Craig SW, Johnson RP: Assembly of focal adhesions: progress, paradigms, and portents. Curr Opin Cell Biol 1996, 8(I):74-85.

25. Albiges-Rizo C, Frachet $P$, Block MR: Down regulation of talin alters cell adhesion and the processing of the alpha 5 beta $I$ integrin. J Cell Sci 1995, I 08(Pt 10):3317-3329.

26. Satou Y, Yamada L, Mochizuki Y, Takatori N, Kawashima T, Sasaki A, Hamaguchi M, Awazu S, Yagi K, Sasakura Y, Nakayama A, Ishikawa H, Inaba $\mathrm{K}$, Satoh N: A cDNA resource from the basal chordate Ciona intestinalis. Genesis 2002, 33(4): $153-154$.

27. Stamm S, Ben-Ari S, Rafalska I, Tang Y, Zhang Z, Toiber D, Thanaraj TA, Soreq H: Function of alternative splicing. Gene 2005, 344: $1-20$.

28. Kontrogianni-Konstantopoulos A, Frye CS, Benz EJ Jr., Huang SC: The prototypical 4.IR-I0-kDa domain and the 4.Ig-10-kDa paralog mediate fodrin-actin complex formation. J Biol Chem 200I, 276(23):20679-20687.

29. He X, Zhang J: Rapid subfunctionalization accompanied by prolonged and substantial neofunctionalization in duplicate gene evolution. Genetics 2005, I69: I I57-I I64.

30. Di Paolo G, Pellegrini L, Letinic K, Cestra G, Zoncu R, Voronov S, Chang S, Guo J, Wenk MR, De Camilli P: Recruitment and regulation of phosphatidylinositol phosphate kinase type Ig by the FERM domain of talin. Nature 2002, 420:85-89.

31. Ling K, Doughman RL, Firestone AJ, Bunce MW, Anderson RA: Type I gamma phosphatidylinositol phosphate kinase targets and regulates focal adhesions. Nature 2002, 420(69II):89-93.

32. Monkley SJ, Zhou XH, Kinston SJ, Giblett SM, Hemmings L, Brown JE, Pritchard CA, Critchley DR, Fassler R: Disruption of the talin gene arrests mouse development at the gastrulation stage. Dev Dyn 2000, 219(4):560-574.

33. Kume M, Dan K: Invertebrate Embryology. New York, Garland; 1988.

34. Kessin RH: Dictyostelium: Evolution, Cell Biology, and the Development of Multicellularity. Cambridge, Cambridge University Press; 200I.

35. Passamaneck YJ, Di Gregorio A: Ciona intestinalis: chordate development made simple. Dev Dyn 2005, 233(I):I-I9.

36. Altschul SF, Gish W, Miller W, Myers EW, Lipman DJ: Basic local alignment search tool. J Mol Biol 1990, 2 I 5:403-4I0.

37. Gill SC, von Hippel PH: Calculation of protein extinction coefficients from amino acid sequence data [published erratum appears in Anal Biochem 1990 Sep; 189(2):283]. Anal Biochem 1989, I 82(2):319-326.

38. Chishti AH, Kim AC, Marfatia SM, Lutchman M, Hanspal M, Jindal $H$ Liu SC, Low PS, Rouleau GA, Mohandas N, Chasis JA, Conboy JG, Gascard P, Takakuwa Y, Huang SC, Benz EJ Jr., Bretscher A, Fehon RG, Gusella JF, Ramesh V, Solomon F, Marchesi VT, Tsukita S, Tsukita S, Arpin M, Louvard D, Tonks NK, Anderson JM, Fanning AS, Bryant PJ, Woods DF, Hoover KB: The FERM domain: a unique module involved in the linkage of cytoplasmic proteins to the membrane. Trends Biochem Sci 1998, 23(8):28I-282.

39. http://www.genoscope.cns.frl.

Publish with BioMed Central and every
Scientist can read your work free of charge
"BioMed Central will be the most significant development for
disseminating the results of biomedical research in our lifetime. "
Sir Paul Nurse, Cancer Research UK
Your research papers will be:
• available free of charge to the entire biomedical community
• peer reviewed and published immediately upon acceptance
• cited in PubMed and archived on PubMed Central
• yours - you keep the copyright
Submit your manuscript here:
http://www.biomedcentral.com/info/publishing_adv.asp

